\title{
Identification of a new human mtDNA polymorphism (A14290G) in the NADH dehydrogenase subunit 6 gene
}

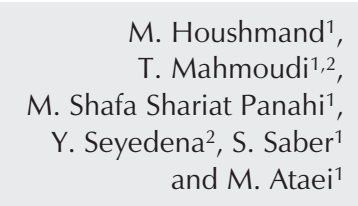

M. Houshmand ${ }^{1}$, M. Shafa Shariat Panahi ${ }^{1}$, and

Correspondence

M. Houshmand

National Research Center for

Genetic Engineering and

Biotechnology

Pajoohesh Blvd

Tehran-Karaj Highway, 17th km

P.O. Box 14155-6343

Tehran

Iran

Fax: +98-21-4458-0399

E-mail: masoudh@nrcgeb.ac.ir

$\ldots \ldots \ldots \ldots \ldots . . . . .$.

Received June 15, 2005

Accepted March 20, 2006
${ }^{1}$ Department of Medical Genetics, National Institute for Genetic Engineering and Biotechnology, Tehran, Iran

${ }^{2}$ Department of Biology, Faculty of Basic Sciences, Shahied Beheshti University, Tehran, Iran

\section{Abstract}

Leber's hereditary optic neuropathy (LHON) is a maternally inherited form of retinal ganglion cell degeneration leading to optic atrophy in young adults. Several mutations in different genes can cause LHON (heterogeneity). The ND6 gene is one of the mitochondrial genes that encodes subunit 6 of complex I of the respiratory chain. This gene is a hot spot gene. Fourteen Persian LHON patients were analyzed with single-strand conformational polymorphism and DNA sequencing techniques. None of these patients had four primary mutations, G3460A, G11788A, T14484C, and G14459A, related to this disease. We identified twelve nucleotide substitutions, G13702C, T13879C, T14110C, C14167T, G14199T, A14233G, G14272C, A14290G, G14365C, G14368C, T14766C, and T14798C. Eleven of twelve nucleotide substitutions had already been reported as polymorphism. One of the nucleotide substitutions (A14290G) has not been reported. The A14290G nucleotide substitution does not change its amino acid (glutamic acid). We looked for base conservation using DNA star software (MEGALIGN program) as a criterion for pathogenic or nonpathogenic nucleotide substitution in A14290G. The results of ND6 gene alignment in humans and in other species (mouse, cow, elegans worm, and Neurospora crassa mold) revealed that the 14290th base was not conserved. Fifty normal controls were also investigated for this polymorphism in the Iranian population and two had A14290G polymorphism (4\%). This study provides evidence that the mtDNA A14290G allele is a new nonpathogenic polymorphism. We suggest follow-up studies regarding this polymorphism in different populations.

\section{Introduction}

Leber's hereditary optic neuropathy $(\mathrm{LHON})$ is a rare neurodegenerative disease of young adults which is maternally inherited and results in blindness due to optic
Key words

- Leber's hereditary optic neuropathy

- ND6 gene

- Mitochondrial DNA mutations

- Single-strand conformational polymorphism

- mtDNA A14290G allele 
ing young adult males (5). LHON is a heterogeneous disease (mutations in the ND1, ND4, and ND6 genes can cause the disease independently). Several mtDNA point mutations have been proposed to be associated with LHON, all in the subunits of the electron-transport chain. Some of these mutations seem to be sufficient to cause the disease (primary mutations). Primary mutations are not found in control individuals, and these mutations evolutionarily alter conserved amino acids. Furthermore, no case has been reported in which an individual harbors more than one primary mutation.

The primary mutations thus far identified are G11778A, G3460A, T14484C, and G14459A $(6,7)$. The primary mutation is necessary but not sufficient for the development of optic neuropathy, and secondary genetic and/or epigenetic risk factors must also be present although they are poorly defined at the present time (8). Other mutations appear to have a synergistic deleterious effect when they occur simultaneously with other mtDNA mutations (secondary mutations). Secondary mutations are also found in control individuals, though at a much lower frequency and they alter less conserved amino acids. Some of the more frequent secondary mutations include G13708A, A4160C, T3394C, and G5244A. Most pathogenic mtDNA mutations in human are heteroplasmic (the cells harbor both mutant and normal mtDNAs) but in most LHON patients the primary mutation is homoplasmic (the cells harbor mutant mtDNAs) $(9,10)$. In order to identify novel mutations, the mtDNA of 14 Persian LHON patients was analyzed by single-strand conformational polymorphism (SSCP) and DNA sequencing techniques.

\section{Material and Methods}

\section{LHON patients}

The patients included in this study under- went ophthalmological examination and were diagnosed to suffer from LHON. All patients were clinically defined as having LHON on the basis of painless, subacute bilateral optic neuropathy. Patients were referred for molecular assessment by consultant ophthalmologists in Farabi Eye Hospital to the Medical Genetics Department of the National Institute for Genetic Engineering and Biotechnology (NIGEB) for evaluation of LHON during a period of 1.5 year (June 2002 to December 2003). Research proposal was first approved by the Hospital Ethics Committee. The mtDNA G11788A, G3460A, T14484C, or G14459A mutations had already been identified in each individual by PCR-RFLP methods as described previously $(11,12)$ and were absent in these patients (13).

Fifty normal matched controls of the same ethnicity were also genotyped to establish the frequency of a new polymorphism detected in the Iranian population. The control consisted of randomly chosen individuals who had no LHON symptoms or a family history of the condition. The patients were not related. All patients and controls were informed about the aims of the study and gave written informed consent to submit to genetic analysis.

\section{mtDNA extraction}

Total DNA (including mtDNA) was extracted from peripheral blood $(5 \mathrm{~mL})$ by salting out. After DNA extraction, about 50 $\mu \mathrm{g}$ DNA at $150-500 \mathrm{ng} / \mu \mathrm{L}$ concentration was obtained.

Three types of PCR were used to assay the ND6 gene in the present study: 1) PCR of first fragment of the ND6 gene for SSCP analysis. This fragment was amplified using 35 cycles of denaturation $\left(60 \mathrm{~s}\right.$ at $\left.94^{\circ} \mathrm{C}\right)$, annealing $\left(60 \mathrm{~s}\right.$ at $\left.62^{\circ} \mathrm{C}\right)$ and an extension of $60 \mathrm{~s}$ at $72^{\circ} \mathrm{C}$. In this PCR one pair of primers (forward 24 mer between 14184 and 14207 and reverse 21 mer between 14340 and 
14360) was used. 2) PCR of a second fragment of the ND6 gene for SSCP analysis. This fragment was amplified using 35 cycles of denaturation $\left(60 \mathrm{~s}\right.$ at $\left.94^{\circ} \mathrm{C}\right)$, annealing (60 $s$ at $61^{\circ} \mathrm{C}$ ) and an extension of $60 \mathrm{~s}$ at $72^{\circ} \mathrm{C}$. In this PCR one pair of primers (forward 21 mer between 14320 and 14340 and reverse 24 mer between 14519 and 14542) was used. 3) PCR of the complete ND6 gene for DNA sequencing analysis. This fragment was amplified using 35 cycles of denaturation $\left(60 \mathrm{~s}\right.$ at $\left.94^{\circ} \mathrm{C}\right)$, annealing $\left(60 \mathrm{~s}\right.$ at $\left.56^{\circ} \mathrm{C}\right)$ and extension of $60 \mathrm{~s}$ at $72^{\circ} \mathrm{C}$. In this PCR one pair of primers (forward 24 mer between 13506 and 13529 and reverse 20 mer between 14821 and 14840) was used. Doublestranded PCR products were visualized with ethidium bromide.

\section{Single-strand conformational polymorphism analysis}

Two types of PCR products (PCR product of the first fragment of the ND6 gene with a 177-bp length and PCR product of the second fragment of the ND6 gene with a 223-bp length) were run on 5.5, 8, and 12\% acrylamide gels with different voltages and for different times at room temperature and at $4^{\circ} \mathrm{C}$, with a gel length of 20 to $30 \mathrm{~cm}$ with or without glycerol. After gel electrophoresis of PCR products, the gels were stained by the silver staining method.

\section{DNA sequencing analysis}

Highly pure PCR products for DNA sequencing were prepared using the PCR product recovery kit from Roche Applied Science (Mannheim, Germany). After the recovery process, $50 \mu \mathrm{L}$ of pure PCR product of each sample was obtained. DNA sequencing of this PCR product was performed by direct sequencing of a 1335-bp fragment with two synthetic primers (ONP 301 from 14360 to 14340 and ONP 302 from 14320 to 14340) in two isolated reactions of DNA sequencing.

\section{Results}

SSCP analysis of both PCR products (first and second fragments of the ND6 gene) under different conditions did not show any nucleotide substitutions. DNA sequencing results revealed twelve nucleotide substitutions in the ND6 gene (seven nucleotide substitutions), the ND5 gene (three nucleotide substitutions) and the CYB gene (two nucleotide substitutions) (Table 1). One polymorphism (A14290G) has not been reported before and was observed in one patient. DNA sequencing of the ND6 gene in 50 normal controls showed that A14290G was present in $4 \%$ of the normal population. The results of ND6 gene alignment in humans and in other species (mouse, cow, elegans worm, and Neurospora crassa mold) revealed that the 14290th base was not conserved. Our study showed that mtDNA A14290G allele is a new nonpathogenic polymorphism.

\section{Discussion}

In the present study, the sequence of the ND6 gene was analyzed in 14 LHON patients not having 4 primary mutations by

Table 1. Nucleotide substitutions observed in an Iranian population.

\begin{tabular}{lccc}
\hline Nucleotide position & Locus & Nucleotide substitution & Amino acid substitution \\
\hline 13702 & MTND5 & G-C & Gly-Arg \\
13879 & MTND5 & T-C & Ser-Pro \\
14110 & MTND5 & T-C & Phe-Leu \\
14167 & MTND6 & C-T & Syn \\
14199 & MTND6 & G-T & Pro-Thr \\
14233 & MTND6 & A-G & Syn \\
14272 & MTND6 & G-C & Phe-Leu \\
14290 & MTND6 & A-G & Syn \\
14365 & MTND6 & G-C & Syn \\
14368 & MTND6 & G-C & Phe-Leu \\
14766 & MTCYB & T-C & Ile-Thr \\
14798 & MTCYB & T-C & Phe-Leu \\
\hline
\end{tabular}

MTND5 = mitochondrial NADH dehydrogenase subunit 5; MTND6 = mitochondrial $\mathrm{NADH}$ dehydrogenase subunit 6 ; $\mathrm{MTCYB}=$ mitochondrial cytochrome $\mathrm{b}$; Syn = synonymous. 
PCR-SSCP and DNA sequencing. Normal controls of the same ethnicity were also genotyped in order to establish the frequency of A14290G. These 14 patients were screened previously and found not to have any of the 4 known primary mutations using PCR-RFLP (13). The ND6 gene as one of the complex I subunits is 525-bp long, harboring most of the primary mutations that cause LHON. Among four primary mutations which cause LHON, T14484C and G14459A occur in the ND6 gene $(14,15)$. In addition, other mutations in the ND6 gene have also been reported in LHON families, such as T14498C (16), A14596T (17), C14568T (18), C14482G (19), C14482A (20), G14453A (21), and T14487C $(22,23)$. This accumulation of mutations in the ND6 gene (as a hot spot region) led us to perform a detailed analysis of this gene in LHON patients. Surprisingly, all of these mutations are located within a stretch of less than 50 amino acids at the amino-terminal end of the ND6 gene. This region is the most conserved part of the ND6 gene and seems to be part of a single transmembrane domain of the polypeptide. Therefore, mutations in this part of the ND6 gene may have a major role in the susceptibility to LHON and associated neurological findings (24). Eleven nucleotide substitutions detected in the present investigation (G13702C, T13879C, T14110C, C14167T, G14199T, A14233G, G14272C, G14365C, G14368C, $\mathrm{T} 14766 \mathrm{C}$, and $\mathrm{T} 14798 \mathrm{C}$ ) were defined as a polymorphism. One of the twelve nucleotide substitutions, an A-to-G transition at nucleotide position 14290 was not previously reported. An A to G transition at nucleotide position 14290 of the glutamic acid codon (GAA) causes a substitution of the GAA to the GAG codon. The GAG codon still codes for the same amino acid (glutamic acid). The A14290G nucleotide substitution was observed only in one patient. The T14110C nucleotide substitution that occurs in the ND6 gene has been identified recently (25). None of the nucleotide substitutions in the ND6 gene found in the present study (C14167T, G14199T, A14233G, G14272C, G14365C, G14368C, and A14290G) are located within the most conserved part of the ND6 gene (the stretch of less than 50 amino acids at the amino-terminal end of the ND6 gene). These findings also confirm previous data about this region which is the most conserved part of the ND6 gene. Since more conserved regions of a gene undergo fewer nucleotide substitutions, most of these nucleotide substitutions in this region will be mutations rather than polymorphisms.

Interpretation of the mtDNA sequence data can be extremely difficult because mtDNA is highly polymorphic and it is often difficult and time consuming to establish whether a mutation is pathogenic or not, particularly if the base change has not been reported before. Of course, several canonical criteria suggest that a novel base change is pathogenic: 1) The base change must affect a site that has been conserved during evolution. If the site is conserved across species, this implies that it is functionally important, and a mutation at this site is likely to be deleterious. The mutation must also be in a region that is functionally important. 2) The mutation should be absent in normal controls. 3) The mutation must not be a known polymorphism (as described by one of the established sequence data bases). 4) The mutation should be reported in several pedigrees with similar phenotypes. 5) There must be a correlation between the levels of mutated mtDNA and severity of symptoms. The mutation segregates with the disease clinically. For heteroplasmic mutations this means that affected individuals have a high percentage of mutated mtDNA, while unaffected individuals have a lower percentage. 6) Deleterious mutations are usually (but not exclusively) heteroplasmic. This implies that the mutation occurred recently and did not have time to "fix" in the female line, or that there was selection against fixation acting at the level of the organism. 7) There is a 
correlation between the levels of mutated mtDNA and the occurrence of respiratory chain deficiency in individual muscle fiber segments or in cybrid cell lines. 8) Analysis of cybrid cell lines demonstrates that the mtDNA mutation alone is sufficient to cause a respiratory chain deficiency.

These stringent criteria depend upon a good knowledge of the polymorphic sites in the background population. Thus, known polymorphic sites could be useful. In the present investigation, the first three criteria were applied to determine whether A14290G is pathogenic or not. The conservation of the 14290th base was assayed using DNA star software (MEGALIGN program) and the same software was used to determine the DNA sequence alignment of the ND6 gene in humans and in other species (mouse, cow, elegans worm, and Neurospora crassa mold). The results of alignment revealed that the 14290th base was not conserved and that there were other nucleotides in other organisms (e.g., T, T, A, and G nucleotides in mouse, cow, elegans worm, and Neurospora crassa mold, respectively). The mutation was also present in $4 \%$ of normal controls of the same ethnic origin and, according to established sequence data bases, the new base change was a previously unknown polymorphism.

Our data suggest that A14290G is a new polymorphism in the Iranian population. To confirm whether this substitution is a polymorphism or a mutation, follow-up studies are needed using other criteria applied to different populations.

\section{References}

1. Carelli V, Ross-Cisneros FN, Sadun AA. Optic nerve degeneration and mitochondrial dysfunction: genetic and acquired optic neuropathies. Neurochem Int 2002; 40: 573-584.

2. Rowland LP. Merritt's neurology. 10th edn. Philadelphia: Lippincott Williams \& Wilkins; 2000.

3. Went LN. Leber hereditary optic neuropathy (LHON): A mitochondrial disease with unresolved complexities. Cytogenet Cell Genet 1999; 8: 153-156.

4. Jenson BK. Nelson textbook of pediatrics. 16th edn. Philadelphia: W.B. Saunders Company, 2000.

5. Scheffler IE. A century of mitochondrial research: achievements and perspectives. Mitochondrion 2001; 1: 3-31.

6. Chalmers RM, Schapira AH. Clinical, biochemical and molecular genetic features of Leber's hereditary optic neuropathy. Biochim Biophys Acta 1999; 1410: 147-158.

7. Dellettre C, Lenaers G, Griffoin JM, Gigarel N, Lorenzo C, Belenguer $P$, et al. Nuclear gene OPAI, encoding a mitochondrial dynaminrelated protein, is mutated in dominant optic atrophy. Nat Genet 2000; 26: 207-210.

8. Howell N. Leber hereditary optic neuropathy: respiratory chain dysfunction and degeneration of the optic nerve. Vision Res 1998; 38 : 1495-1504.

9. Rose MR. Mitochondrial myopathies: genetic mechanisms. Arch Neurol 1998; 55: 17-24.

10. Pulkes T, Hanna MG. Human mitochondrial DNA diseases. Adv Drug Deliv Rev 2001; 49: 27-43.

11. Jun AS, Brown MD, Wallace DC. A mitochondrial DNA mutation at nucleotide pair 14459 of the NADH dehydrogenase subunit 6 gene associated with maternally inherited Leber hereditary optic neuropathy and dystonia. Proc Natl Acad Sci U S A 1994; 91: 6206-6210.

12. Kobayashi $Y$, Sharpe H, Brown N. Single-cell analysis of intercellu- lar heteroplasmy of mtDNA in Leber hereditary optic neuropathy. Am J Hum Genet 1994; 55: 206-209.

13. Houshmand M, Sharifpanah F, Tabasi A, Sanati MH, Vakilian M, Lavasani SH, et al. Leber's hereditary optic neuropathy: the spectrum of mitochondrial DNA mutations in Iranian patients. Ann N Y Acad Sci 2004; 1011: 345-349.

14. Jun AS, Trounce IA, Brown MD, Shoffner JM, Wallace DC. Use of transmitochondrial cybrids to assign a complex I defect to the mitochondrial DNA-encoded NADH dehydrogenase subunit 6 gene mutation at nucleotide pair 14459 that causes Leber hereditary optic neuropathy and dystonia. Mol Cell Biol 1996; 16: 771-777.

15. Oostra RJ, Van Galen MJ, Bolhuis PA, Bleeker-Wagemakers EM, Van den BC. The mitochondrial DNA mutation ND6*14,484C associated with Leber hereditary optic neuropathy, leads to deficiency of complex I of the respiratory chain. Biochem Biophys Res Commun 1995; 215: 1001-1005.

16. Leo Kottler B, Christ AM, Zrenner E, Wissinger B. Leber's hereditary optic neuropathy: clinical and molecular genetic results obtained in a family with a new mutation at nucleotide position 14498 in the ND6 gene. Ger J Ophthalmol 1996; 5: 233-240.

17. De Vries DD, Went LN, Bruyn GW, Scholte HR, Hofstra RM, Bolhuis PA, et al. Genetic and biochemical impairment of mitochondrial complex I activity in a family with Leber hereditary optic neuropathy and hereditary spastic dystonia. Am J Hum Genet 1996; 58: 703711.

18. Wissinger B, Besch D, Baumann B, Fauser S, Christ-Adler M, Jurklies B, et al. Mutation analysis of the ND6 gene in patients with Leber's hereditary optic neuropathy. Biochem Biophys Res Commun 1997; 234: 511-515.

19. Howell N, Bogolin C, Jamieson R, Marenda DR, Mackey DA. mtDNA mutations that cause optic neuropathy: how do we know? Am J Hum 
Genet 1998; 62: 196-202.

20. Valentino ML, Avoni P, Barboni P, Pallotti F, Rengo C, Torroni A, et al. Mitochondrial DNA nucleotide changes C14482G and C14482A in the ND6 gene are pathogenic for Leber's hereditary optic neuropathy. Ann Neurol 2002; 51: 774-778.

21. Ravn K, Wibrand F, Hansen FJ, Horn N, Rosenberg T, Schwartz M. An mtDNA mutation, $14453 \mathrm{G} \rightarrow \mathrm{A}$, in the NADH dehydrogenase subunit 6 associated with severe MELAS syndrome. Eur $J$ Hum Genet 2001; 9: 805-809.

22. Solano A, Roig M, Vives-Bauza C, Hernandez-Pena J, GarciaArumi E, Playan A, et al. Bilateral striatal necrosis associated with a novel mutation in the mitochondrial ND6 gene. Ann Neurol 2003; 54:
527-530.

23. Ugalde C, Triepels RH, Coenen MJ, van den Heuvel LP, Smeets R, Uusimaa J, et al. Impaired complex I assembly in a Leigh syndrome patient with a novel missense mutation in the ND6 gene. Ann Neurol 2003; 54: 665-669.

24. Fearnley IM, Walker JE. Conservation of sequences of subunits of mitochondrial complex I and their relationships with other proteins. Biochim Biophys Acta 1992; 1140: 105-134.

25. Sudoyo $H$, Suryadi $H$, Lertrit $P$, Pramoonjago $P$, Lyrawati D, Marzuki $\mathrm{S}$. Asian-specific mtDNA backgrounds associated with the primary G11778A mutation of Leber's hereditary optic neuropathy. J Hum Genet 2002; 47: 594-604. 